atoll is not new. Darwin says, "A bank at the proper depth beneath the surface would give rise to a reef which could not be distinguished from an atoll formed during subsidence." Murray says, "Very early in the history of such an atoll, and while yet several fathoms submerged, the corals situated in the central parts would be placed at a disadvantage." It does not, however, appear to have been contemplated that the inclosed lagoon would, under any circumstances, without some further agency than the simple growth of the rim, be so deep as it appears to me, from the cases above cited, that it can be ; nor, so far as I can find, have any such instances been before remarked.

Darwin notices the case of the Chagos Bank, but, on the authority of Captain Moresby, he states that the rim is dead, and concludes that life was killed by subsidence, and he apparently also infers that it will not grow to the surface.

I can find no fresh evidence on this particular reef, but for some of the banks in the China Sea I have the independent testimony of two of the officers employed in their survey, Staff-Commanders Tizard and Petley, R.N., that the coral growth is most luxuriant.

Touching for a moment on the point of the formation of banks at a proper distance below the surface; the investigation of banks in the Atlantic, recently described by Mr. J. Buchanan, shows that banks with almost walllike slopes are growing up by the accumulation of organisms.

Turning to barrier reefs, similar instances can be found. Off the coast of the island of Palawan, a shallow rim is forming on the edge of the bank which stretches from the island to a distance varying from 15 to 30 miles, having a general depth on it of 40 fathoms. The length of the rim is 250 miles, and it consists of streaks and patches of coral with from 4 to 30 fathoms on them.

On the south of the eastern end of New Guinea, a formation, known to navigators as the sunken barrier, lines the edge of a bank similar to the above, and is of precisely the same character. Its length is 140 miles, and the depth between it and the land varies from 30 to 60 fathoms.

Dr. Guppy has recently pointed out some smaller instances of the same tendency in the Solomon Islands, and has made some remarks on the formation of barrier reefs in the same sense as my suggestions. I am not therefore advancing anything novel, but simply pointing out evidence which tends to show that the principle may be carried further than has hitherto been supposed.

Looking now at the fringing class, how comes it that so many wide reefs of this character exist, which, if Mr. Murray's contention be correct, should surely show more signs of the formation of a lagoon channel than they do?

Take the case of Rodriguez, in the Indian Ocean, with which I am personally intimately acquainted. Here a fringing reef surrounds the western sides of the island for a width of $4 \frac{1}{2}$ miles. There are narrow channels it is true, but so shallow that in many places boats cannot pass at low water. The island is situated in the heart of the strong trade winds, and the reefs are exposed to a heavy sea, which, with a rise of tide of nearly 6 feet, gives every facility for scour and rapid change of water.

I am not disputing the fact that calcareous dead organisms are dissolved by carbonic acid. I am no chemist, and moreover the Challenger observations amply prove it, but I would ask Mr. Murray if there is not a great difference between the position of small shells falling in water which completely surrounds them whilst they are constantly coming in contact with fresh particles of it, and of the more or less solid mass of a coral reef, which can only be attacked on its upper side to advantage, and where the resultant fine mud covers and protects the remaining rock, especially in the case of lagoon channels, when the bottom is partly composed of detritus from theland.

At the bottom of a lagoon of any depth, moreover, the motion of the water must often be comparatively slight, and the action consequently extremely slow.

The rotten state of the surface of every coral reef awash with the water shows that this disintegration is going on, but the fact that for large areas it remains awash, and must have so remained for ages, seems to me to point to the supposition that the removal of matter is too insignificant to account for the formation of deep lagoon channels in this manner, though doubtless it may explain the shallow pools and creeks found in all fringing reefs.

I have addressed myself solely to one point in this many-sided question, but I may add my opinion that, before any explanation which will fully account for the almost infinite variety of coral formations, can be given, much more knowledge of details of the complex conditions under which they may grow is required.

Certain knowledge of the depths at which different corals and other lime-secreting animals live under varying circumstances; of the amount of food carried in the different strata and in different waters; of the effect of the velocity of the currents that bring the food to the banks; and more accurate surveys on large scales, especially of the shapes and contours of coral reefs, and of their composition, are all wanting. These details must greatly affect coral growth, and the results must greatly vary. On the other hand, similar results may be brought about by different causes.

It may surprise some to learn how little in the preliminary matțer of surveys alone has been done in the principal coral-reef regions, especially in the Pacific, which is generally quoted; and consequently how very inexact our knowledge is of the depth both inside and outside of the majority of atolls in the world, and also of the state of the bottom of the sea, on which it is very possible that many elevations may be found in the condition of those to which I have called attention.

In the Pacific the vast majority of islands have been merely sketched without a single sounding having been taken, either inside or outside lagoons.

I append a few statistics relating to the larger coral groups to show our position in this respect; merely remarking that the waters of the Fiji and the Society Islands are the only ones which can be said to be in any sense surveyed.

\begin{tabular}{lcccc} 
& & \multicolumn{4}{c}{ No. of Islands. } \\
Paunotu Islands & $\ldots$ & 74 &. \\
Ellice &, & $\ldots$ & I0 & $\ldots$ \\
Gilbert &, & $\ldots$ & I6 & $\ldots$ \\
Marshall &, & $\ldots$ & 30 & $\ldots$ \\
Caroline &, & $\ldots$ & 43 &. \\
Tonga &, & $\ldots$ & 6 groups &..
\end{tabular}

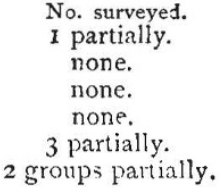

W. J. L. WharTON.

\section{THE AKKAS, A PYGMY RACE FROM CENTRAL AFRICA.}

$A \mathrm{~T}$ the last meeting of the Anthropological Institute Prof. Flower gave a description of two skeletons of Akkas, lately obtained in the Monbuttu country, Central Africa, by Emin Pasha, and by him presented to the British Museum. Since this diminutive tribe was discovered by Schweinfurth in 1870 , they have received considerable attention from various travellers and anthropologists, and general descriptiors and measurements of several living individuals have been published, but no account of their osteological characters has been given, and no specimens have been submitted to careful anatomical examination. The two skeletons are those of fully adult people, a male and a female, but unfortunately neither is quite complete. The evidence they afford entirely corroborates the view, previously derived from external measurements, that the Akkas 
are among the smallest, if not actually the smallest, people upon the earth. There is no reason to suppose that these skeletons were selected in any way as exceptional specimens, yet they are both of them smaller than any other normal skeletons known, smaller certainly than the smallest Bushman skeleton in any Museum in this country, and smaller than any out of twenty-nine skeletons of the diminutive inhabitants of the Andaman Islands, of which the dimensions have been recorded by Prof. Flower in a previous paper communicated to the Institute. The most liberal calculation of the height of these two skeletons places that of the male at about an inch below 4 feet, and the female at less than an inch above. We may say 4 feet, or 1 '219 metre, as the average height of the two, while a living female of whom Emin Pasha has sent careful measurements is but $\mathrm{r} \cdot 164$ metre, or barely 3 feet ro inches. The results previously obtained from the measurements of about half-a-dozen living Akkas are not quite so low as these, varying from 1.216 to $1 \cdot 420$, and give a mean for both sexes of $1 \cdot 356$, or 4 feet $5 \frac{1}{2}$ inches. Schweinfurth's original measurements were unfortunately lost, and the numbers since obtained are quite insufficient for establishing the true average of the race, especially as it is not certain that they were all pure-bred specimens.

In the list given in the third edition of Topinard's "Anthropologie" (187.9) only two races appear which have a mean beight below I.500 metres, viz. the Negritos of the Andaman Islands I 478 , and the Bushmen I 404 . Of the real height of the former we have abundant and exact evidence, both from the living individuals and from skeletons, which clearly proves that they considerably exceed the Akkas in stature. That this is also the case with the Bushmen there is little doubt, although the measurements of this diminutive race are less numerous and carefully made.

The point of comparative size being settled, it remains to consider to what races the Akkas are most nearly allied. That they belong in all their essential characteristics to the black or Negroid branch of the human species there can be no doubt, in fact they exhibit all the essential characteristics of that branch even to exaggeration. With regard to the somewhat more rounded form of head (the cephalic index in these examples being $74^{\circ} 4$ and $77^{\circ} 9$ respectively), Hamy has long since pointed out that in equatorial Africa, extending from the west coast far into the interior, are scattered tribes of Negroes, distinguished from the majority of the inhabitants of the continent by this special cranial character, as well as by their smaller stature. The Akkas are grouped by Hamy and Quatrefages as members of this race, to which the distinctive name of "Negrillo" has been applied. Their small size has naturally led some anthropologists, including Schweinfurth, to ally them to the diminutive African race inhabiting the southern part of the continent-the Bushmen; but beyond certain characters met with in the whole Negroid branch, including the frizzly hair, there is little in common between them. The Bushmen are a very strongly marked race, and both their external appearance and osteological characters are so exceptional that they can never be confounded with any other. The natives of the Andaman Islands have also very distinctive characters, which they do not share with the Akkas, whose position all recent investigations show to be that assigned to them by Hamy as members of the Negrillo division of the Negroid branch of mankind. It is possible that these people gave origin to the stories of pygmies so common in the writings of the Greek poets and historians, and whose habitations were often placed near the sources of the Nile. The name "Akka," by which, according to Schweinfurth, the tribe now call themselves, has, singularly enough, been read by Mariette Pasha by the side of a portrait of a dwarf on a monument of the ancient Egyptian empire.

\section{REV. JOHN HEWITT JELLETT, D.D., D.C.L}

I $\mathrm{T}$ is with extreme regret that we announce the death of the Reverend the Provost of Trinity College, Dublin. He died last Sunday evening after a very short illness.

The Provost was present in his usual health at the Spring Commencements, which were held on the I4th inst. in the Hall of Trinity College; on the 16 th he was not quite well; on the 18 th some dangerous symptoms appeared ; and the end came, painlessly and unexpectedly, on the Igth inst.

John Hewitt Jellett was born at Cashel in the county of Tipperary on December 25, I8I7. He entered Trinity College, Dublin, when seventeen years of age. Obtaining a Scholarship in 1836 , he graduated as a Senior Moderator and Gold Medallist in Mathematics in 1837, and three years afterwards he obtained a Fellowship.

In 1848 , he was appointed to the Professorship of Natural Philosophy; in 1870 , on the death of the Rev. Dr. Luby, he was co-opted a Senior Fellow of Trinity College, and on the death of the Rev Dr. Lloyd, in $188 \mathrm{r}$, he was nominated by the Crown to the Provostship.

Twenty years ago he was made one of the Commissioners of National Education in Ireland, and he was President of the Royal Irish Academy from I 869 to 1873 .

In 1850 , Jellett published his well-known "Treatise on the Calcủlus of Variations," a subject which had engaged the attention of some of the noblest mathematical intellects of the world. The volume contains improvements of previously existing methods, which, had they been given as so many separate treatises, would in themselves have formed no ordinary title to fame; but the author's aim was rather to compile a memoir which would enable the earnest student to be on a level with the knowledge he had himself attained to, however little that aim might be to his own glory.

For this work the Royal Irish Academy awarded Jellett in $185 \mathrm{I}$ their Cunningham Gold Medal. In 1872 appeared the "Treatise on the Theory of Friction," a work well known and highly appreciated. In addition to these volumes a number of scientific memoirs were from time to time published by him in the Transactions of the Royal Irish Academy, and in Leonville's Journal de Mathématique, of which perhaps the more important were on the "Equilibrium and Motion of an Elastic Solid" and "On Researches in Chemical Optics."

Like other well-known mathematicians of the Dublin University, Jellett was as much thought of for his pulpit discourses as for his scientific memoirs. He was of good presence, had a clear articulation and a very persuasive style; and his appearance in the pulpit of the College chapel was always welcomed. When he dwelt on the moral difficulties of the Old Testament, none went their way without being impressed by the straightforward honesty of the man.

Occupying a very conspicuous position in a University city like Dublin, the Provost seemed to command the respect of all. Some perhaps there are who would have preferred that the head of so ancient a seat of learning should have taken no part in modern political strife ; but, even amid the feverish excitement of party warfare, the Provost of Trinity College, though he often fearlessly and eloquently put forward his own views, did so without giving offence to any.

Intimately associated, from the year 1834 , with the life of the College over which he at the last presided, the Provost knew much of, and was a prime mover in, many of the changes which have marked out a new life in the place. Within its walls he was known and respected, while the tribute to his memory paid by all classes of the Dublin citizens is a striking proof of how he was loved.

This is not the place to dwell on the intense loss his 